\title{
Developmental Changes in Intestinal Glycosyl-Transferase Activities
}

\author{
M. C. BIOL,' A. MARTIN, M. RICHARD, AND P. LOUISOT \\ Department of General and Medical Biochemistry, INSERM, CNRS U.189, Lyon-Sud Medical School, B.P. 12, \\ 69600 Oullins Cedex, France
}

\begin{abstract}
The carbohydrate composition of some intestinal glycoproteins has been demonstrated previously to be modified during development. To evaluate the role of the enzymatic mechanisms of glycosylation, the activities of three soluble and microsomal glycosyl-transferases were studied during postnatal development in rat intestinal mucosa. Nonexistent as soluble forms in the cell sap from suckling rats, the membrane-bound $\mathrm{N}$-acetylgalactosaminyl-, sialyl-, and fucosyl-transferases showed different activities in microsomal fractions before weaning. The $\mathrm{N}$ acetylgalactosaminyl-transferase activity was constant whereas the sialyl-transferase activity, which was maintained at a rather high level until the age of $2 \mathrm{wk}$, decreased just before weaning, while the fucosyl-transferase activity declined progressively from birth to weaning. After weaning, the three enzymatic activities progressively enhanced until adult age. Their variable behaviors on several glycoprotein acceptors may suggest the presence of several sialyl- and fucosyl-transferases with differences in specificities, varying in different ways according to age. Such developmental modifications in intestinal glycosylation patterns may be linked with certain transformation observed in the carbohydrate level of mucus or membranebound glycoproteins and related to the profound modifications in nutritional status at the weaning period. (Pediatr Res 22: 250-256, 1987)
\end{abstract}

The glycoconjugates play a prominent part in the small intestinal tract as mucus and cellular membrane components. The pre- and postnatal developmental patterns of digestive glycoprotein enzymes [such as sucrase, maltase, isomaltase, alkaline phosphatase, or aminopeptidase (1-4] have been studied with regard to the level of enzyme activity. However, in terms of carbohydrate composition, little is known about the structure of such enzymes, except for $\gamma$-glutamyl-transferase (5) and alkaline phosphatase $(6,7)$ which have been demonstrated to possess differences in the sialic acid content of fetal and adult-type enzymes.

Modifications in the electrophoretic behavior (1) and in the glycosylation of the microvillus membrane glycoproteins $(8-10)$ have been noted. Age-related differences in the types of mucus glycoproteins synthesized in the small intestine were also demonstrated (11). In all cases, the variations observed between

Received September 8, 1986; accepted March 27, 1987

Correspondence Dr. P. Louisot, Department of General and Medical Biochemistry. INSERM-CNRS U 189, Lyon-Sud Medical School, BP 12,69921, Oullins Cedex, France.

Supported by grants from the Institut National de la Santé et de la Recherche Médicale (U.189), the Centre National de la Recherche Scientifique and the University of Lyon, Lyon-Sud Medical School.

Chargé de Recherches au Centre National de la Recherche Scientifique. newborn and adult animals were in glycoprotein fucosylation or sialylation. Moreover, the biosynthesis and the intracellular transport of glycoproteins were modified in rat duodenal absorptive cells as a function of age (12).

Some intestinal glycosyl-transferases, responsible for the biosynthesis of carbohydrate chains of the glycoconjugates, have been well characterized (13-15). The intestinal glycosylation processes are known to depend on different factors: distribution along the intestinal tract (16) and along the crypt-to-villus axis $(17,18)$, administration of some drugs $(19,20)$, vitamin $A$ deficiency $(21)$, or nutritional status $(22,23)$. With regard to development, little is known about intestinal glycosyl-transferases. Only galactose incorporation has been studied in fetal, neonatal and adult rat colon (24) and small intestines (25). In a previous study (22), we showed that soluble intestinal fucosyltransferase activity increased gradually in young adult rats on a standard diet for $4 \mathrm{wk}$ and that this increase was modulated by high-protein and high-fat diets. In order to gain insight into this phenomenon, three glycosyl-transferases were studied in the small intestinal mucosa of growing rats from birth to adult age and the results are reported in the present paper.

\section{MATERIALS AND METHODS}

Animals and cellular fractionation. Seven groups of SpragueDawley male rats (IFFA-CREDO, Les Oncins, France) from 4 days to $9 \mathrm{wk}$ of age were studied in parallel (three litters of ten 4-day-old rats, two litters of 10 rats 1 and 2 wk of age, six 3-wkold rats and four rats in each of the 5-, 7-, and 9-wk groups). These animals were weaned at approximately 18-20 days. Animals were sacrificed by rapid decapitation at $0800 \mathrm{~h}$ and the small intestines were removed, washed with cold $0.9 \% \mathrm{NaCl}$, and weighed. For suckling rats 4 and 7 days of age, the small intestines were opened, cut into small pieces and directly homogenized. In this case, the muscular tissue (which was not destroyed by homogenization) was discarded by filtration on cheese-cloth. For 2- to 9-wk-old rats, the mucosa was collected by scraping the intestine with a microscope plate and was maintained at $4^{\circ} \mathrm{C}$.

The homogenate was prepared in $10 \mathrm{mM}$ Tris- $\mathrm{HCl}, 10 \mathrm{mM}$ $\mathrm{KCl}, 10 \mathrm{mM} \mathrm{MgCl}, 250 \mathrm{mM}$ sucrose, and $\mathrm{pH} 7.4$ buffer $(9 \mathrm{ml} /$ $\mathrm{g}$ of wet tissue) with a Potter-Elvejhem homogenizer and centrifuged at $30,000 \times g$ for $20 \mathrm{~min}$. The supernatant was then centrifuged for $2 \mathrm{~h}$ at $100,000 \times g$, leading to sedimentation of a microsomal fraction and to a soluble cell sap. Enzymatic activities were studied on these two fractions.

Determinations of enzymatic activities. Three glycosyl-transferase activities (EC 2.4.1, XDP-sugar: glycoprotein glycosyltransferase) were determined: fucosyl-, sialyl- and $\mathrm{N}$-acetylgalactosaminyl-transferases. The principle of enzymatic activity determinations was based upon the amount of ${ }^{14} \mathrm{C}$-sugar incorporated by the subcellular fractions from the substrate nucleoside diphospho- ${ }^{14}$-sugar $(20 \mathrm{nCi}$ per assay). Specific radioactivities of 
sugar-nucleotides (New Fngland Nuclear) were: GDP-fucose (262 (i/mol), CMP-N-acetylneuraminic acid $(319)(\mathrm{Ci} / \mathrm{mol})$, and UDP-N-acetylgalactosamine $(47 \mathrm{Ci} / \mathrm{mol})$. Incorporation was determined with zero order kinetics from () to $30 \mathrm{~min}$, at optimal conditions for $\mathrm{pH}$ and temperature, and in the presence of manganese (except for sialyl-transterase) as described previously (22).

The glycosyl-transferase activities were studied either with endogenous acceptors or with exogenous acceptors. (ilycoprotein exogenous acceptors (asialofetuin, asialoserotransferrin. and asialomucin) were prepared according to Ko and Raghupathy (26) and used at 20 $\mu \mathrm{M}$ in incubation mixtures. These acceptors permitted a higher incorporation of fucose and were used in saturating concentration so that variations in amount of endogenous acceptors could be eliminated. Moreover, the use of exogenous acceptors allowed examination of glycosyl-transferase specificities. The endogenous and exogenous acceptor reactions were stopped by addition of $20 \%$ trichloroacetic acid and the radiolabelled protein precipitates were collected on (iF/B Whatman glass fiber filters: radioactivity was determined by liciuid scintillation counting after placing the filters in Toluene Scintillator (Packard).

To determine (x-(1-2)-fucosyl-transferase activity, phenyl-galactose $(1 \mathrm{mM})$ was used as a specific substrate (27). After the reaction, the incubation mixture was passed through a $I$ )owex 1 column $(0.5 \times 1 \mathrm{~cm})$ in order to eliminate unreacted (iDP. fucose. On lyophilization, radioactive sugars were separated by paper chromatography (Whatman 3MM) using ethyl acetate pyridine/water $(12: 5: 4)$ in a $4-h$ run. Sugars were detected by aniline phtalate reaction and the quantification of incorporated fucose was obtained by counting the radioactivity along the paper.

The activity of enzymes able to hydrolyze the substrates of the glycosylation reaction (glycosvl-nucleotide pyrophosphatases: $\mathrm{EC}$ 3.6.1.21) and the activity of enzymes which could act on the synthesized products (glycosidases) were indirectly estimated according to Mookerjea and Yung (28) in all subcellular fractions (using same conditions ats in determination of the glveosyltransferase activities). $\triangle M P$ was added at $10 \mathrm{mM}$ in microsomal fractions and $2 \mathrm{mM}$ in cell sap hecause of its inhibitory effect on pyrophosphatases.

In order to study the possible proteolvtic degradation of the protein acceptors or enzymes the activity of acid and neutral proteases was estimated in the subcellular fractions with the method of Hille ot al. (29), using ${ }^{3} \mathrm{H}$-acetyl-hemoglobin as substrate.

The DNA content of the intestinal mucosa samples was determined as described by Burton (30) and protein content was determined according to (iornall et al. (31).

Inalvsis of fincosilated asialoferum. In order to distinguish the fucosylation of ()-glycans (predominant in mucins) from that of $\mathrm{N}$-glycans, asialofetuin (fucosylated for 30 to $180 \mathrm{~min}$ ) was submitled to a $\beta$-elimination reaction according to Spiro and Bhoyroo (32). The incubation was performed in $0.1 \mathrm{~V} \mathrm{VaOH}$ ().8 M NaBH $\mathrm{M}_{4}$ for $68 \mathrm{~h}$ at $37^{\circ}$ (', after which the mixture was adjusted to pli 5.0 with $4 \mathrm{~N}$ acetic acid. chromatographed on a Dowex 50 column $(0.5 \times 1 \mathrm{~cm})$ and eluted with $0.01 \mathrm{~V}$ formic acid. The reaction products were separated on a Sephadex ( 25.5 column $(2.5 \times 170 \mathrm{~cm})$ eluted with a $(0.1 \mathrm{M}$ pyridine-acetic acid pH 5.0 buffer. The column was calibrated with known oligosaccharides (as described in Fig. 4) and the radioactivity in $(0.5-\mathrm{ml}$ aliquots was determined after addition of $5 \mathrm{ml}$ F:mulsifier Scintillator 299 (Packard)

Statistical analisis. For each experiment with the sen groups of rats (as described above). six or eight determinations of the glycosyl-transferase activities were made on each sample of the subcellular fractions. Two to four different experiments were conducted depending on the enzyme studied. In Figures 1 to 3. results are expressed as means $\pm \mathrm{SD}$ ) of the combined groups of values and compared by Student's / test. In Table 1, means were compared by Mann and Whitney's I test.
REST!ITS

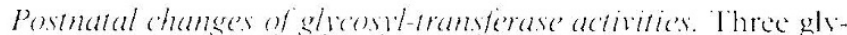
cosyl-transferases (fucosyl-, stalyl- and $\mathrm{V}$-acetylgalactosaminyltransferases) were studied in intestinal microsomal fractions and cell saps obtained from 4-day-old to 9-wk-old rats.

As seen in Figure $1 a$, the microsomal $\mathrm{N}$-acetylgalactosaminyltransferase specific activity remained at a low kevel with ho significant changes) until the age of 2 wks. Just after weaning. enzyme activity rapidly and significantly increased to a high

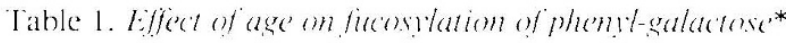

$$
\begin{array}{cc}
\text { Age of rat (wh) } & \text { Fucosylation rate } \\
3 & 39 \pm 30 \\
7 & 72 \pm 41+
\end{array}
$$

* Fucose and fucosylated phenyl-galactose (I*uc-( by paper chromatography as described in "Materials and methods." Results are expressed as femtomol of Fuc-( ial-Ph synthesifed mm $\mathrm{mg}^{-1}$ protein (means $\pm \mathrm{SI}$ ) on four determinations) and compared by the Mann and Whitneys l: test.

$+p<0 .(01$
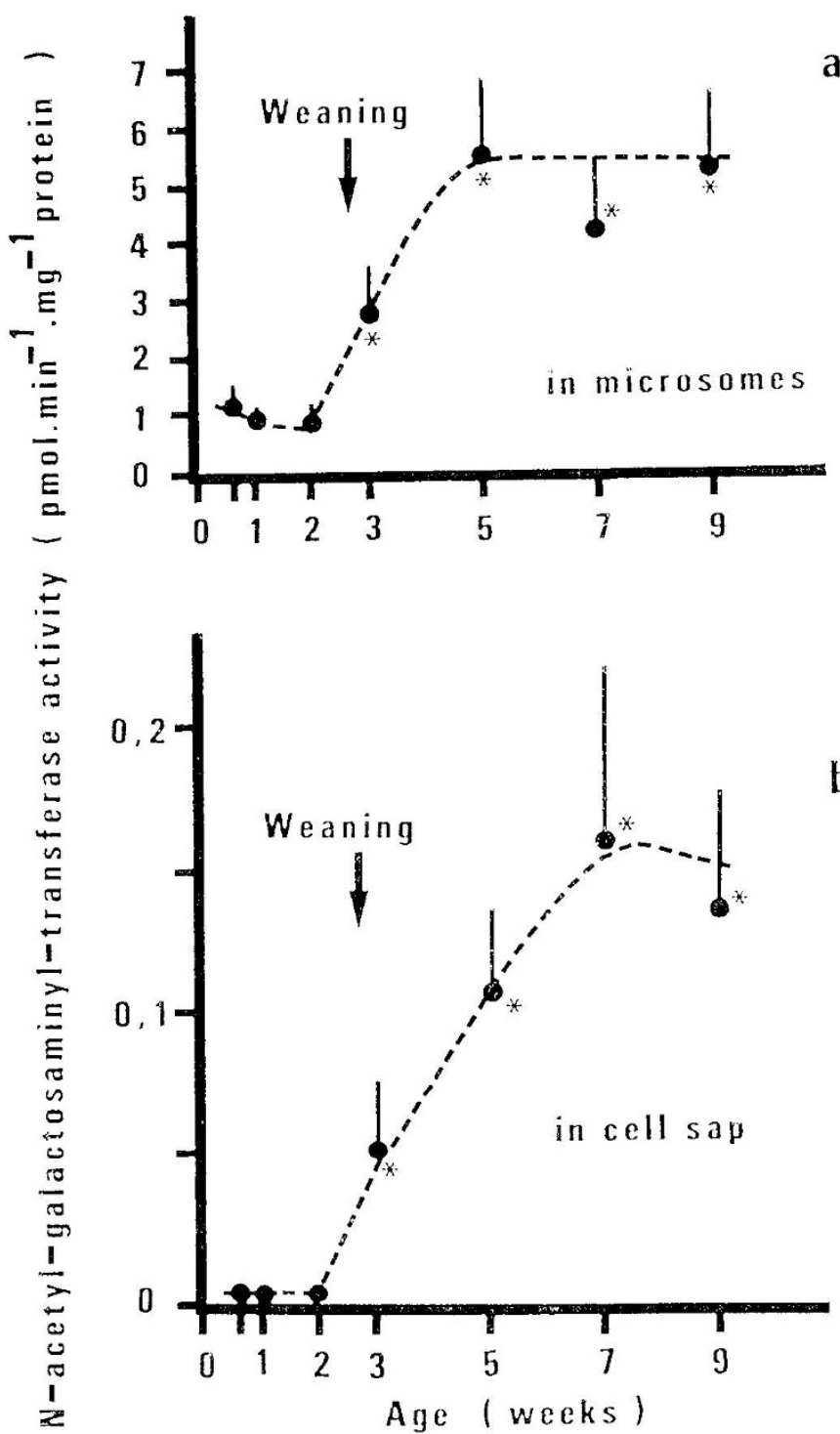

Fig. I. Influence of age on V-acetylgalactosaminyl-transterase specific activity in microsomes $(a)$ and cell sap $(b)$ of rat intestinal mucosa. Fateh point represents the mean $\pm \mathrm{SD}$ ) of 16 determinations of the enamatic activity. obtained from two different samples of the subcellular fratens. $* p<0 .(0) 1$ in comparison to 2 -wk results. 
plateau reached after $5 \mathrm{wk}$, whereafter no further significant changes were observed; overall, enzyme activity increased 5-fold. In the soluble fraction (Fig. $1 b$ ), the $\mathrm{N}$-acetylgalactosaminyltransferase activity was not detectable before weaning, but from this point increased progressively and then plateaued at 7 to 9 wk. Maximal enzyme activity was considerably higher in the microsomal fraction compared to the cell sap fraction ( 5 and 0.2 $\mathrm{pmol} \cdot \mathrm{min}^{-1} \cdot \mathrm{mg}^{-1}$ protein respectively).

The results of the sialyl-transferase assays are shown in Figure 2. Sialic acid was not incorporated on endogenous acceptor in either microsomal or cell sap fractions. For the exogenous glycoprotein acceptors, the microsomal sialyl-transferase displayed different behaviors (Fig. 2a). On asialomucin (Mds), its activity was linearly enhanced from birth to adult age with at least a 10fold increase. On the other hand, the incorporation of sialic acid into asialofetuin (Fds) was slightly but significantly increased from 4 days to $1 \mathrm{wk}(p<0.020)$ and $2 \mathrm{wk}(p<0.005)$. It was followed by a highly significant $(p<0.001)$ depletion just after

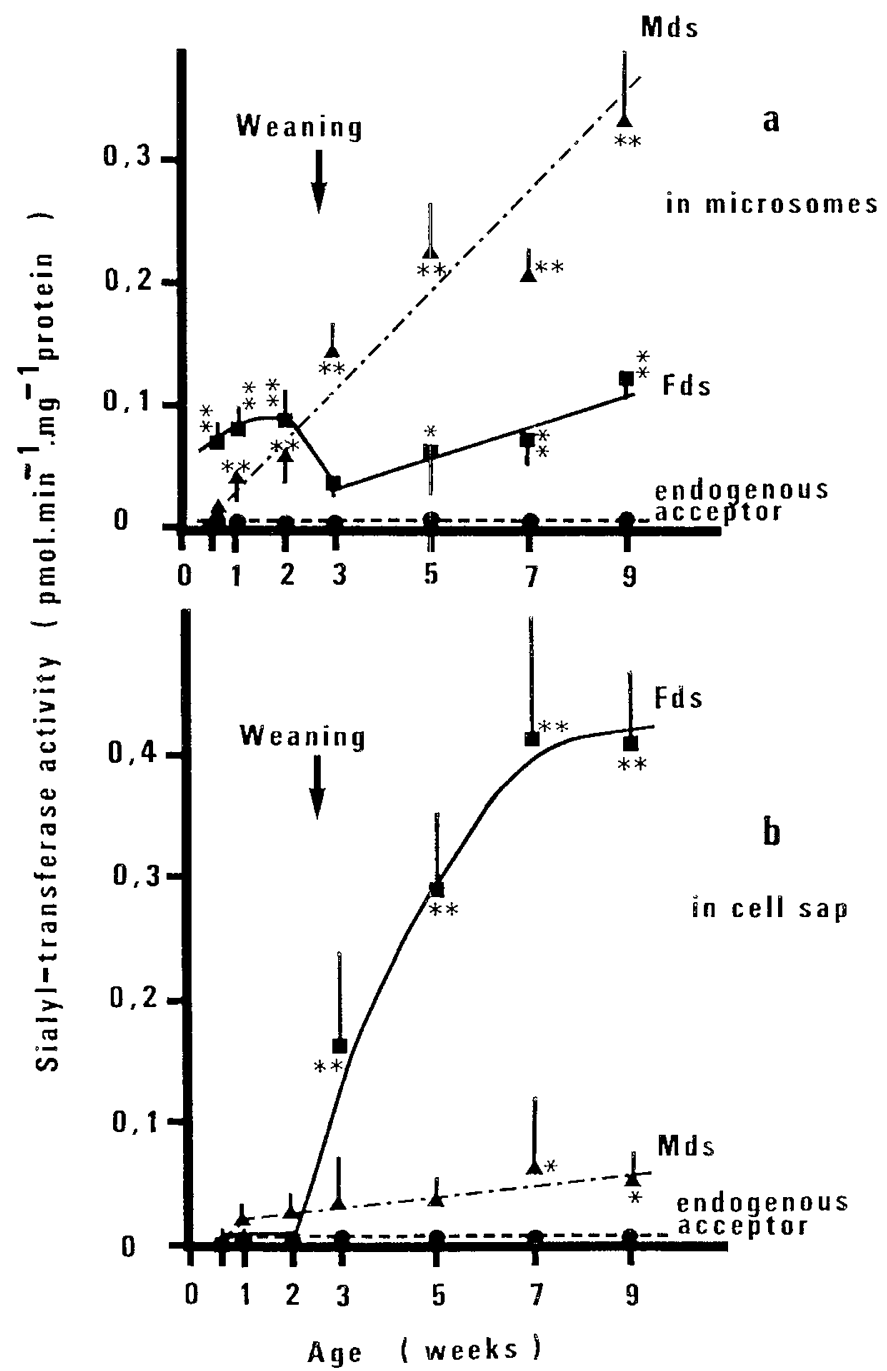

Fig. 2. Influence of age on sialyl-transferase specific activity in microsomes $(a)$ and cell sap $(b)$ of rat intestinal mucosa. The activities were determined on endogenous acceptor (---) or glycoproteinic exogenous acceptors $[F d s=$ asialofetuin $(-)$, Mds $=$ asialomucin $(---)]$ and expressed as means \pm SD of 16 determinations of the enzymatic activity obtained from two or three different samples of the subcellular fractions. In microsomes: with Fds as acceptor, results are compared to those obtained for 3-wk-old rats whereas, with $\mathrm{Mds}$ as acceptor, results are compared to those obtained for 4-day-old rats. In cell sap, with Fds, results are compared to those obtained for 2-wk-old rats; with Mds, results are compared to 1 -wk results: ${ }^{*} p<0.002,{ }^{* *} p<0.001$. weaning. Then, a linear and significant increase of sialic acid incorporation was observed in samples from rats 3 to $9 \mathrm{wk}$ of age. In the cell sap (Fig. $2 b$ ), the incorporation of sialic acid into Mds appeared at a low level after the 1st wk, then a slight but regular increase was noted. However, differences were significant only for animals 7 to $9 \mathrm{wk}$ of age, as compared to young animals. On Fds, the sialyl-transferase activity showed a different pattern in cell sap as compared to the microsomal fraction. No sialic acid incorporation could be determined in suckling rats but, at the weaning period, a drastic and progressive increase of sialyltransferase activity was observed which reached a steady state in adult rats.

Figure $3 a$ shows the results obtained for the microsomal fucosyl-transferase activity determinations. In suckling rats, the enzyme specific activity determined for endogenous acceptor was characterized by a rapid decline to a minimum level reached just before the weaning period. Then, from the 3 rd to the 9th wk, a progressive and significant increase in this activity was observed. In the presence of exogenous glycoprotein acceptors, fucosyl-transferase activity was always enhanced, but the observed increase differed according to the acceptor used. The fucose incorporation increased rather regularly when asialoserotransferrin (STds) was used as substrate; the ratio of fucose incorporation for STds versus endogenous acceptor was respectively $2.1,2.0$, or 1.7 at 1,5 , or 9 wk. On the contrary, when using asialofetuin ( $\mathrm{Fds}$ ), the increase was greater in adult than in suckling or young rats, since the ratio of the fucose incorporation for Fds versus endogenous acceptor varied from 2.2 or 1.5 at 1 or $3 \mathrm{wk}$, respectively, to 3.7 and 3.5 at 5 and $9 \mathrm{wk}$, respectively.

In the cell sap, fucose was incorporated only into exogenous acceptors (Fig. $3 b$ ), but the incorporation level remained low as compared to the microsomal fraction. On asialoserotransferrin, the fucose incorporation was low and increased very slightly with age. Significant enhancement appeared only at 5, 7, and $9 \mathrm{wk}$ of age as compared to incorporation obtained for the youngest rats. On asialofetuin, the fucose incorporation was undetectable before weaning then increased after two weeks and plateaued after 7 to 9 wk.

When results were expressed in total activities (per intestine), the glycosylation patterns observed for these three soluble glycosyl-transferases were quite similar to those observed when specific activities were described (data not shown). In contrast, in the microsomal fraction, a relative drop in the level of the sugar incorporation could be noted in suckling rats as compared to young postweaning and adult rats (as shown in Fig. $3 c$ for the fucosyl-transferase total activity). Indeed, in contrast to results observed in specific activities there was no significant difference in total activity between 2-wk-old rats and younger animals, except for 4-day-old rats when asialofetuin was used as acceptor $(p<0.020)$. These results could be explained by significant differences in intestinal weight before and after weaning. Although the mucosal weight could not be exactly determined for the 4- and 7-day-old rats, it was clear from the intestine weights that the mucosa weight markedly increased at weaning. Indeed, the small intestine weights were, respectively, $0.5 \pm 0.1$ and 0.7 $\pm 0.1 \mathrm{~g}$ for rats 1 and $2 \mathrm{wk}$ of age, $3.6 \pm 0.4 \mathrm{~g}$ for young weaned rats $3 \mathrm{wk}$ of age and $6.7 \pm 0.6 \mathrm{~g}$ for adult rats. The study of activities in relation to DNA content gave similar glycosylation patterns as described above for total activities (data not shown).

Analysis of fucosylated asialofetuin. The fucosylation of asialofetuin by the cell saps obtained from intestines of 3- and 7-wkold rats was investigated. The labeled asialofetuin was submitted to $\beta$-elimination and the results of Sephadex G25 chromatography of reaction products is shown in Figure 4. As previously described (33), the three peaks were identified as fucosylated products. Peak 1 corresponded to a long oligosaccharide resulting from the $\mathrm{N}$-glycan chain, peak 2 to a fucosylated tetrasaccharide of O-glycan [probably a Fuc-Gal-(NeuAc)-GalNAc resulting from an incompletely desialyzed carbohydrate chain], and peak 3 to a fucosylated trisaccharide (the sequence of which could be Fuc-Gal-GalNAc). In 3-wk-old as in 7-wk-old rats, the fucose 

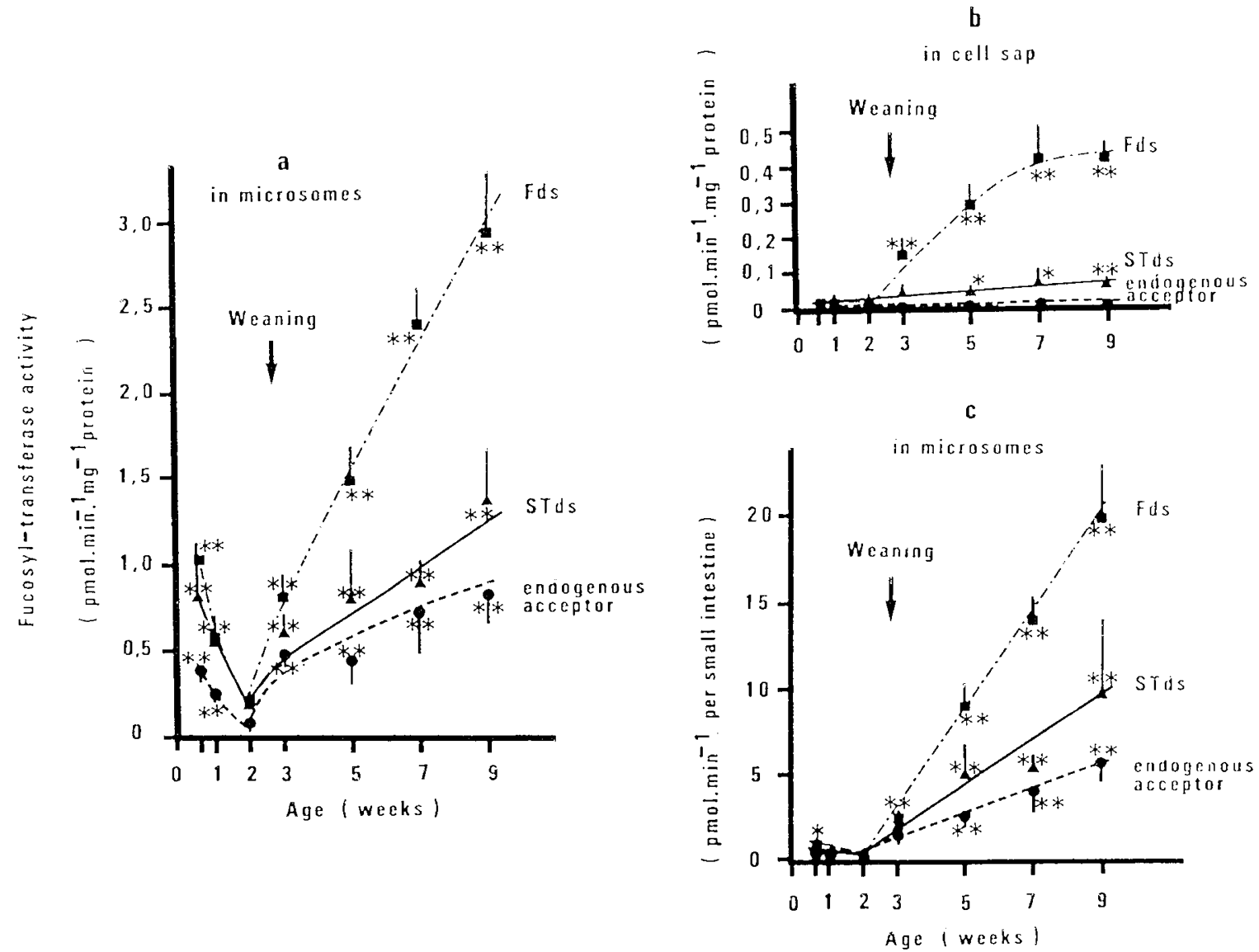

Fïg. 3. Influence of age on fucosvl-transferase specific activity in microsomes (a) or ceil sap (h) and on microsomal fuccosvl-1ransferase total activity (c) of rat intestinal mucosa. The activities were determined on endogenous acceptor $(---)$ or exogenous acceptors freds = astialofetuin

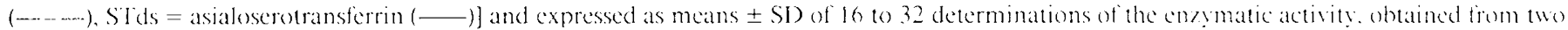
to four different samples of the subcellular fractions. ${ }^{*} p<0.020 .{ }^{* *} p<0.001$ for comparison with 2 -wk results.

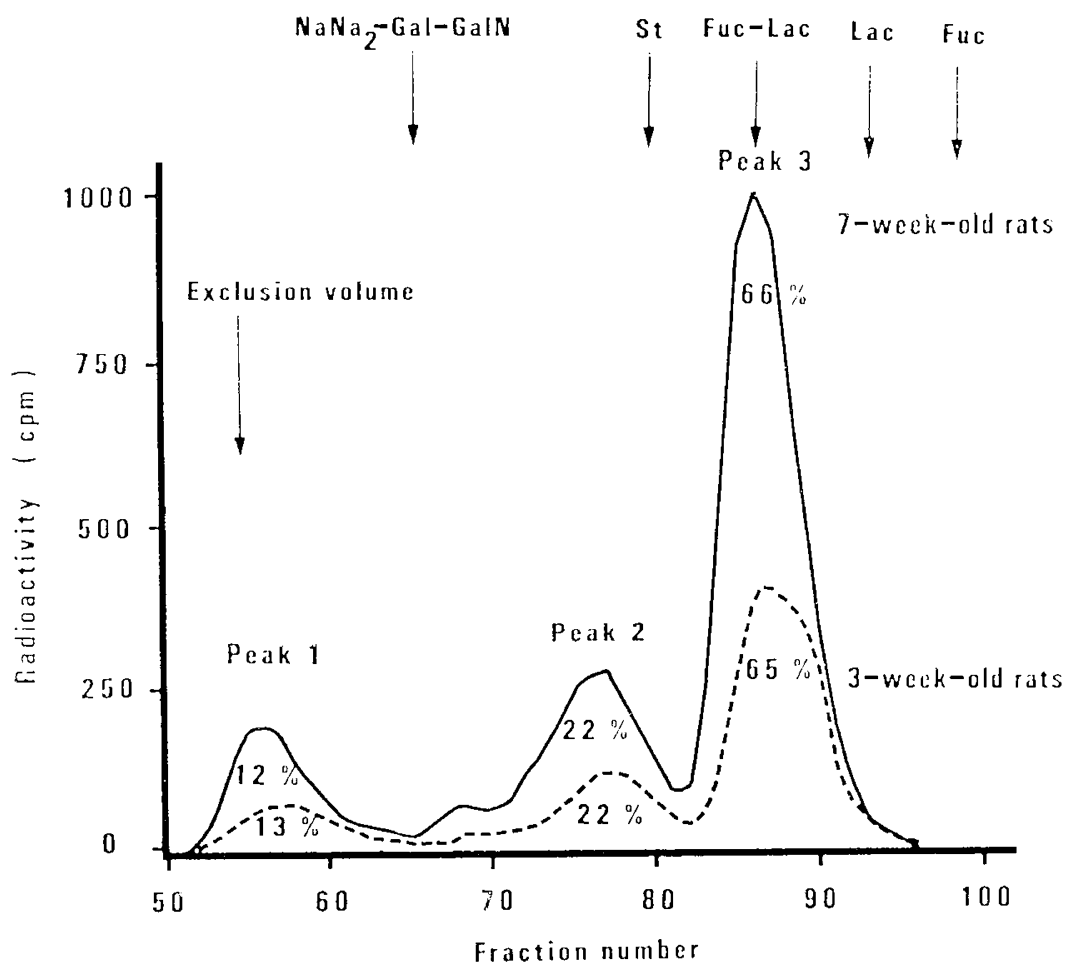

Fï. 4. (hromatography on Sephadex (i25 of B-elimination products of fucosylated asialofetuin obtained from intestinal mucosia of i-wk-old (-) and 7-wk-old rats (-). See "Materials and methods" for details. Vumbers express radioactivity of each peak as a pereentage of the

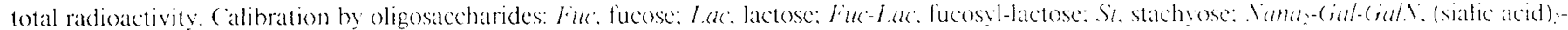
galactose-N-acetylgalactosamine. 
incorporation predominated in the smallest O-glycan (65\%). This incorporation was higher in 7-wk-old than in 3-wk-old rats, but there was no change in the relative distribution of the radioactivity among the three peaks for the two ages.

Fucosylation of oligosaccharidic acceptor. Previous work had indicated that the fucosylation of the asialo- $O$-glycan may occur only at site 2 of the galactose residue, as demonstrated by high voltage electrophoresis in borate buffer (34). Fucose incorporation into phenylgalactose, used as a specific acceptor for $\alpha-(1-2)$ linkage of fucose (27), was higher in 7-wk-old than in 3-wk-old rats (Table 1). This result confirms an increase in the activity of a fucosyl-transferase with $\alpha-(1-2)$ specificity.

Control of the glycosylation process. Next, we wanted to determine whether the observed changes in glycosyltransferase activity were related to changes in enzyme activity or whether there was some influence of interfering reactions, namely sugar-nucleotide breakdown and proteolytic activity.

Sugar-nucleotide breakdown was studied by chromatography of the reaction mixture supernatant. The glysolation mixture always contained AMP which, at $10 \mathrm{mM}$ in microsomal fractions and at $2 \mathrm{mM}$ in cell sap fractions, was a good inhibitor of sugarnucleotide breakdown; higher concentrations of AMP inhibitored glycosyl-transferase activities in cell sap. Table 2 presents the results of the sugar-nucleotide degradation studies in the cell sap. In this subcellular fraction, the degradation of UDP-Nacetylgalactosamine and GDP-fucose by glycosyl-nucleotide pyrophosphatases or osidases was always weak at each time point except for very young suckling rats 4 days of age. However, in this case, the degradation did not exceed $15 \%$ of the sugarrucleotides used in the reaction mixture, whereas it was only about $2 \%$ or less at all the other time points. The substrate CMPsialic acid remained completely undegraded at all times. In microsomal fractions, the breakdown patterns of the sugar-nucleotides were quite similar, but degradations (in presence of AMP) were about $50 \%$ of those observed in cell sap (results not shown).

Proteolytic activities were always slight. Nevertheless, in cell sap, they were highest in suckling rats and decreased thereafter to a constant low level by 3 wk (Table 2). In microsomes, the results were similar but neutral proteases varied from 3.8 to 0.7 $\mathrm{pm} \cdot \mathrm{mn}^{-1} \cdot \mathrm{mg}^{-1}$ protein and acid proteases from 1.2 to $0.1 \mathrm{pm}$. $\mathrm{mn}^{-1} \cdot \mathrm{mg}^{-1}$ protein.

Thus, the degradation of substrates or products of the glycosylation reactions was seen to be minimal and therefore most likely did not contribute significantly to the variations observed in glycosyl-transferase activities.

\section{DISCUSSION}

We have demonstrated the existence of important modifications in the activities of three enzymes responsible for the gly-

Table 2. Substrate degradation in cell sap during glycosylation process*

\begin{tabular}{lllllllllll} 
& \multicolumn{8}{c}{ Age } \\
& \multicolumn{1}{c}{ Days } & \multicolumn{1}{c}{ Wk } \\
& -4 & 1 & 2 & 3 & 5 & 7 & 9 \\
\hline Sugar-nucleotide breakdown & & & & & & & & \\
$\quad$ UDP-N-acetylgalactosamine & 7.6 & 1.4 & 0.5 & 0 & 0.6 & 0.2 & 0 \\
$\quad$ GDP-fucose & 1.4 & 0.2 & 0.3 & 0.2 & 0.2 & 0.3 & 0 \\
CMP-sialic acid & 0 & 0 & 0 & 0.1 & 0.1 & 0 & 0.1 \\
& & & & & & & \\
Proteolytic activity & & & & & & & & \\
$\quad$ Acid proteases & 3.5 & 2.1 & 1.7 & 0.2 & 0.4 & 0.4 & 0.4 \\
$\quad$ Neutral proteases & 1.8 & 1.0 & 0.6 & 0.2 & 0.2 & 0.2 & 0.3 \\
\hline
\end{tabular}

* For sugar-nucleotide breakdown, results are given as pmol. ${ }^{14} \mathrm{C}$ sugarnucleotide degraded $\cdot \mathrm{mn}^{-1} \cdot \mathrm{mg}^{-1}$ protein, in presence of AMP. For proteolytic activities, results are expressed as pmol. ${ }^{3} \mathrm{H}$ hemoglobin degraded $\cdot \mathrm{mn}^{-1} \cdot \mathrm{mg}^{-1}$ protein (means of two determinations). cosylation of proteins in rat intestinal mucosa in relation to weaning period. These variations cannot be explained by the effect of degrading enzymes involved in the glycosylation process (such as glycosyl-nucleotide pyrophosphatases and osidases), by the effect of proteases, or by a modification of the localization of the glycosyl-transferases since these activities did not vary inversely in microsomal and soluble fractions.

$\mathrm{N}$-acetylgalactosaminyl-transferase activity, nonexistent in cell sap and stable in the microsomal fraction from suckling rats, increased after weaning until adult age. These observations are in agreement with the report that $\mathrm{N}$-acetylgalactosamine content of mucus glycoproteins is considerably enhanced in adult rats as compared to 6-day-old animals (11). Some investigators have suggested that adult rat mucus glycoproteins, and microvillus membrane-bound glycoproteins, may contain a high percentage of side chains with $\mathrm{N}$-acetylgalactosamine and galactose at nonreducing termini $(9-11)$.

With regard to sialyl-transferase, its activity was variable according to the glycoprotein acceptor utilized. Using asialomucin as substrate, the soluble and the microsomal enzyme activities increased linearly from birth to adulthood. In contrast, with asialofetuin, the soluble sialyl-transferase activity appeared only at weaning, whereas the microsomal activity showed a more complex pattern: it increased until the age of $2 \mathrm{wk}$, then decreased at weaning and increased again at adult ages. A difference in specificity of sialyl-transferases can be suggested by this variable behavior toward acceptors since bovine asialomucin is known to show a $(2-6)$ specificity for $O$-glycans while asialofetuin can present (2-3) and (2-6) specificities with $\mathrm{O}$ - and $\mathrm{N}$-glycans (3, 36). Differences in the developmental pattern of enzymes synthesizing sialyl-(2-3)-lactose and sialyl-(2-6)-lactose are known in liver (37). Furthermore, the sialic acid level in glycoproteins varies according to the type of intestinal membrane studied. The sialic acid level was previously described as similar in mucus glycoproteins of 6-day-old and adult rats (11). In microvillus membranes, the sialic acid content was the highest in suckling rats with a maximum at the age of 14 days, then the content decreased at weaning and continued at a low level in postweaning animals (8). Some authors have suggested that the desialylation of brush border membranes plays a physiological role in the differentiation process of enterocytes during the postnatal period and that it may be under hormonal control (38). Thus, the difficulty in finding a single specific relationship between sialyl-transferase activity and sialic acid content in intestinal glycoproteins is evident. Nevertheless the importance of the weaning period in modifications of sialic acid levels has long been recognized. The investigations of Tojyo (7) on intestinal alkaline phosphatase (well known to be a glycoprotein enzyme) corroborate this observation. This enzyme, which produced only one band on gel electrophoresis of samples taken from fetal and suckling rats, showed three bands in postweaning and adult rats, and neuraminidase treatment modified the proteins' mobility. Moreover, $\gamma$-glutamyl-transferase appeared in two different types in the small intestine: a sialic acid-rich fetal type and a sialic acid-poor adult type (5), but these investigators did not examine the structure of the enzyme obtained from suckling animals.

The activity of soluble fucosyl-transferase was evident only after weaning but the microsomal enzyme, while very active at birth, declined in activity until weaning and to a similar level for the two glycoprotein acceptors. After weaning, the soluble and microsomal enzymes exhibited the same behavior. The increase of fucosyl-transferase activity observed with asialofetuin as acceptor was higher than with asialoserotransferrin. As the relative enhancement with asialofetuin was more pronounced with age, a difference in specificity of fucosyl-transferases could be postulated, as was the case for sialyl-transferase. Indeed, we have recently observed the existence of a $\beta$-galactoside $\alpha$-(1-2)-fucosyl-transferase and a $\beta$-N-acetylglucosaminide $\alpha$-(3/4)-fucosyltransferase in intestinal mucosa (33).

After separation of the products of $\beta$-elimination of the fucosylated asialofetuin, the absolute amount of the three products 
was greater in 7-wk-old as compared to 3-wk-old rats: however. a similar partition of the fucose incorporated in peaks corresponding to $\mathrm{N}$-glycans or to ()-glycans was observed. The mucintype ()-glycans were predominant. On the other hand. the study of the incorporation of fucose into phenylgalactose. generally accepted as relative to ( $x-(1-2)$-specificity, confirms that there are quantitative differences of fucose incorporation between 3and 7-wk-old rats. () interest will be more complete investigations on the specificity of purified intestinal fucosyl-transferase: such studies are presently in progress in our laboratory (33).

In previous studies of the carbohydrate composition of mucus glyeoproteins (11) or microvillus membranes (8-10). some investigators have demonstrated that the fucose content is higher in weaned or adult rats than in suckling rats. Moreover. the behavior of microvillus membranes toward specific lectins corroborates these results $(8-10)$. A reent study on biosynthesis and transport of intestinal glycoproteins has shown that after intraluminal injection, fucose was almost nonexistent in rats 6 days of age whereas it was highly incorporated in 24-day-old rats (12). The age-related changes of fucosyl-transferase activity can partly explain such results.

In the rat intestine. the developmental glycosylation pattern shows two important variation stages: birth and weaning. Our study shows two distinct periods from birth to adult age for the modifications of glycosyl-transferase activities, where weaning seems to be the critical point. Some age-related modifications in sialylation or fucosylation of mucus glycoproteins and microvillus membrane bound glvcoproteins can be explained by the level of activity of the enzymes responsible for sialic acid or fucose transfer. In suckling animals. glycoprotein enzymes such as maltase, lactase. or alkaline phosphatase are present in high amounts as both soluble and membranous forms. whereas they exist only in the membranous form in intestine of adult animals (39, 40). According to some authors (39). the solubility of these enzymes could be due either to modifications of their V-terminal areas which prevent (or makes unstable) their insertion into membranes or to poorly developed recognition phenomena possibly involving carbohydrate sequences.

The rat small intestine undergoes a concert of morphological and enzymatic changes at the weaning period and profound structural transformations. These developmental changes (partly related to the activities of glycosyl-transferases) result in a functionally mature intestine containing all of the necessary digestive enzymes to cope with the carbohydrate-rich diet of adulthood In other publications (22,23,41). we have demonstrated that intestinal glycosvl-transferase activities are diet sensitive and are modified as well by quantity as well as by quality of nutrients. Moreover, modifications in glveosvlation may be important for bacteria-enterocyte interations and the glycosylation processes could possibly be influenced by intestinal microflora. Indeed. introduction of microorganisms into the intestine can modify glveosylation processes. For example, observations on conventionalized mice compared to germ-free mice showed that the synthesis of sugar chains in microvillus membrane-associated glycoproteins was affected by the introduction of intestinal microorganisms and that fucosyl-transferase activity was modified (42).

It is apparent that our understanding of the mechanisms of intestinal glycoprotein biosynthesis. in relation to development. is incomplete. The relations between glycosyl-transferase activities and glycoprotein structure are often demonstrable. but the reasons for these profound modilications in relation to development are still to be determined.

Acknowledgments. The authors thank Dr. D). J. Fitzgerald. International Agency for Research on (ancer. I.yon. France for the english revision of the manuseript and are indebted to $\mathrm{I}$. Hugueny and $\mathrm{F}$. I.erme for their skilled technical assistance and to M. Bourdat for typing.

\section{RFFFRFNCFS}

1. Cialand (i. Forstner (i(i 1974 Isolation of microvillus plasma membranes from suckling rat intestine. The influence of premature induction of digestive enzumes by injection of cortisol acetate. Biochem J 1.44:293-302

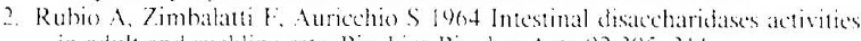
in adult and suckling rats. Biochim Biophys Act:1 92:305-311

3. Yeh KY, Moog F 1975 Development of the small intestine in the hypophesetomized rat. I. (jrowth, histology and activity of athaline phosphatase. maltase and sucrase. Dew Biol $47: 156.172$

4. Aurichio S. Stellato A. De Vira B 1981 Develement of hrush-borde peptidases in human and rat small intestine during fetal and neonatal life. Pediatr Res $15: 991-995$

5. Kottgen E. Reulter W. Cierok W1976 liwo diflerent gamma-glutamyltansterase during developmen of liver and small intestine: a letal (sialo-) and an aduit (asialo-)glycoprotein. Biochem Biophys Res (ommun 72:61 6o

6. Lafont J. Roriere J 1973 Heterogeneity dependent on age intestinal alkaline phosphatase in the rat. (omp Biochem Physiol $45: 135-145$

7. Tojyo Y 1984 Developmental changeover in rat duodenal alkaline phosphatase Comp Biochem Physiol 77:4:37-4+1

8. Bresson JI. Herseovies A. Walker W: 1982 Diflerences in microvillus memhrane glycoprotein fucosylation with age and differentiation. (iastrocenterol(og: $5: 1025$

4. Mahmood A. Torres-Pinedo R 1983 Postnatal changes in lectin binding to microvillus membranes from rat intestine. Biochem Biephys Res (ommun $113 \cdot 400-400$

10. Torres-Pinedo R. Mahmood A 1984 Postnatal changes in hounthesis of microvillus membrane glycans of rat smail intestme. I. fvidence of a developmental shift from terminal sialylation to fucosylation. Biochem Biophys Res (ommun 125:56-553

11. Shub MD). Pang KY. Swann DA. Wolker WA 1983 Age-related changes in chemical compostton and physical propertices of mucus glycoproteins from rat small intestine. Biochem i $215: 4(0) 5-411$

12. Yet KY, Moog f 1984 Biosynthesis and transport of glvooproteins in the smalt intestinal epithelium of rats. 1. Dewelopmental change and eflect of hopephosectoms. I)es Biol 101:+4(1-402

13. Frot-couta/ J. (int R 1971 Proprictes de trose glycosyl-transferases de lat muqueuse intestinale de rat. Biochimic 5.3.595-601

14. Kim YS. Perdomo I. Nordberg (i.) 1971 (ilvoprotein biosunthesis in small intestinal mucosa. I. A studo of glocost-transferases in microsomal subtrac. tions. J Biol (hem 24 $405466-5476$

15. Martin A. Iouisot P 1976 Bioss nthesis of glveoproteins in the intestinal mucosa. I. Soluble state of tive glycosyl-transferases. Int J Biechem ": 505

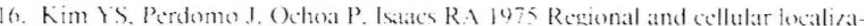
tion of glveos:l-transterases in rat small intestine. (hanges in cnemes with differentiation of intestinal epithelial cefl. Biochem Biophys letat 301 . 30 50

7. Weiser MIM 1973 intestinal epithedial cell surface membrane glycoprotem synthesis. 1 . An indicator of cellulat diflerentiation, I Biol ( hem $245: 2536$ $25+1$

15. Weiser M1M 1973 Intestmal epithelial cell surfice membrane ghengetein synthesis. II. (ilvensyl-transterases and endogemous acecptors of the indiflerentiated cell surlace membranc. I Biol ( hem 248:2542 2548

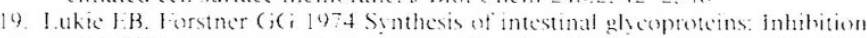
of $1-{ }^{1+4}(")$-glucosamine incorporation he phenylbutazone in sitro. Biechim

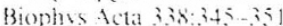

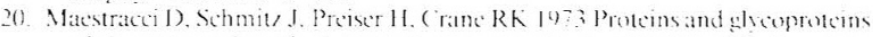
of the human intestinal brush-border membrane. Biochim Bophy leta $323: 113124$

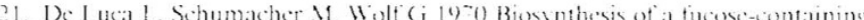
glveopeptide from small intestine in normal and sitamin A-deficient conditions. J Biol ( hem 245.551 455

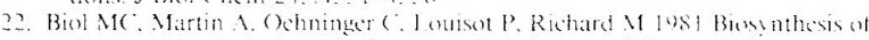
glveoproteins in the intestinal muecosa. II. Influcnec of diets. Ann Vute Metah $25: 269-280$

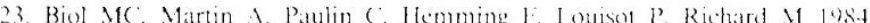
(ilycosyl-transterase atetrities in the tat intestinal mucosa: (ompartison hetween standard commerctal and semi-synthetic diets Ann Vutr Metath $28: 52-64$

24. Iamont J1. Ventola 1978 ( ialactoss/-transferase in fetal, neonatal and adult colon: Relationshin to differentiation. Im J Phosiol $235: 121:-121$

25. (arlson D)M. David J. Rutter WJ 19:3 (ialactossl-translerase activitics in pancreas. liver and gut of developing rat. Arehs Biochem Biophws 157605 612

26. Ko (iKH. Raghupathy ( 1971 (ilycoprotein biosynthesis in the develeping rat brain. I. Microsomal galactessl-transferase utiling endogenous and

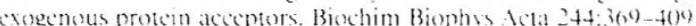

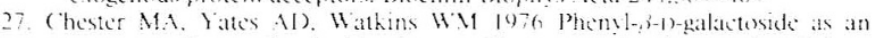
acceptor substrate for the blood group 11 genc-associated guanosine diphos-

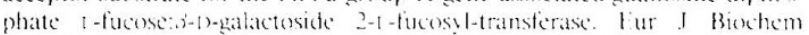
(19):58:3-592

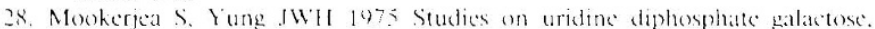
p!rophosphatasc and uridine diphosphate galactose glycoprotein galactosy!transferase activities in microsomal membranes. Archs Bochem Biophys 166:22:-236

29. Hille MB. Barret A. Dingle Jl. Fell HB 1970 Microassas for athepsin 1) shows an unexpected effect of creloheximide on limb-bone rudiments in organ culture, 1:yp (ill Res $61: 47()-472$ 
30. Burton K 1966 A study of the conditions and mechanism of the diphenylamin reaction for the colorimetric estimation of deoxyribonucleic acid. Biochem $\mathrm{J} 62: 315-323$

31. Gornall AG, Bardawill CJ, David MM 1949 Determination of serum proteins by means of biuret reaction. J Biol Chem 226:497-509

32. Spiro RG, Bhoyroo VD 1974 Structure of the O-glycosidically linked carbohydrate units of fetuin. J Biol Chem 249:5704-5717

33. Martin A, Biol MC, Richard M, Louisot P 1987 Purification and separation of two soluble fucosyltransferase activities of small intestinal mucosa. Int $\mathbf{J}$ Biochem (in press)

34. Kobata A, Yamashita K, Tachibana Y 1978 Oligosaccharides from human milk. Methods Enzymol 50:216-220

35. Schachter H 1978 Glycoprotein biosynthesis. In: Horowitz MI (ed) The Glycoconjugates, vol II. Academic Press, New York, pp 88-181.

36. Montreuil J 1980 Primary structure of glycoprotein glycans. Basis for the molecular biology of glycoproteins. Adv Carbohydr Chem Biochem 37:157223

37. Hudgin RL, Schachter M 1972 Evidence for two CMP-N-acetylneuraminic acid:lactose sialyl-transferases in rat, porcine, bovine and human liver. Can J Biochem 50:1024-1028

38. Kraml J, Kolinska J, Kadelcova L, Zakostelecka M, Zdenek L 1984 Effect of hydrocortisone on the desialylation of intestinal brush-border enzymes of the rat during postnatal development. FEBS Lett 172:25-28

39. Forstner G, Forstner J 1979 Segmental distribution of soluble neutral maltase activity in suckling rat intestine. Levels vary independently of membranebound maltase and lysosomal enzymes during development. Biochim Biophys Acta 586:250-257

40. Yedlin ST, Young GP, Scetharam B, Seetharam S, David H 1981 Characterization and comparison of soluble and membranous forms of intestinal alkaline phosphatase from the suckling rat. J Biol Chem 256:5620-5626

41. Biol MC, Martin A, Louisot P, Richard M 1986 Structure and metabolism of glycoproteins: nutritional regulation. World Rev Nutr Diet 50:122-185

42. Umesaki Y, Toyama K, Mutai M 1982 Biosynthesis of microvillus membraneassociated glycoproteins of small intestinal epithelial cells in germ-free and conventionalized mice. J Biochem 92:373-379 